\title{
Trois bois gravés de Gustave Doré
}

Jérôme Schweitzer

\section{(2) OpenEdition}

Journals

Édition électronique

URL : https://journals.openedition.org/rbnu/2002

DOI : $10.4000 /$ rbnu.2002

ISSN : 2679-6104

\section{Éditeur}

Bibliothèque nationale et universitaire de Strasbourg

\section{Édition imprimée}

Date de publication : 1 novembre 2013

Pagination : 62-65

ISBN : 9782859230517

ISSN : 2109-2761

\section{Référence électronique}

Jérôme Schweitzer, "Trois bois gravés de Gustave Doré », La Revue de la BNU [En ligne], 8 | 2013, mis en ligne le 01 novembre 2013, consulté le 21 mai 2021. URL : http://journals.openedition.org/rbnu/ 2002 ; DOI : https://doi.org/10.4000/rbnu.2002

\section{c) (i)(2)}

La Revue de la BNU est mise à disposition selon les termes de la Licence Creative Commons Attribution - Pas d'Utilisation Commerciale - Partage dans les Mêmes Conditions 4.0 International. 


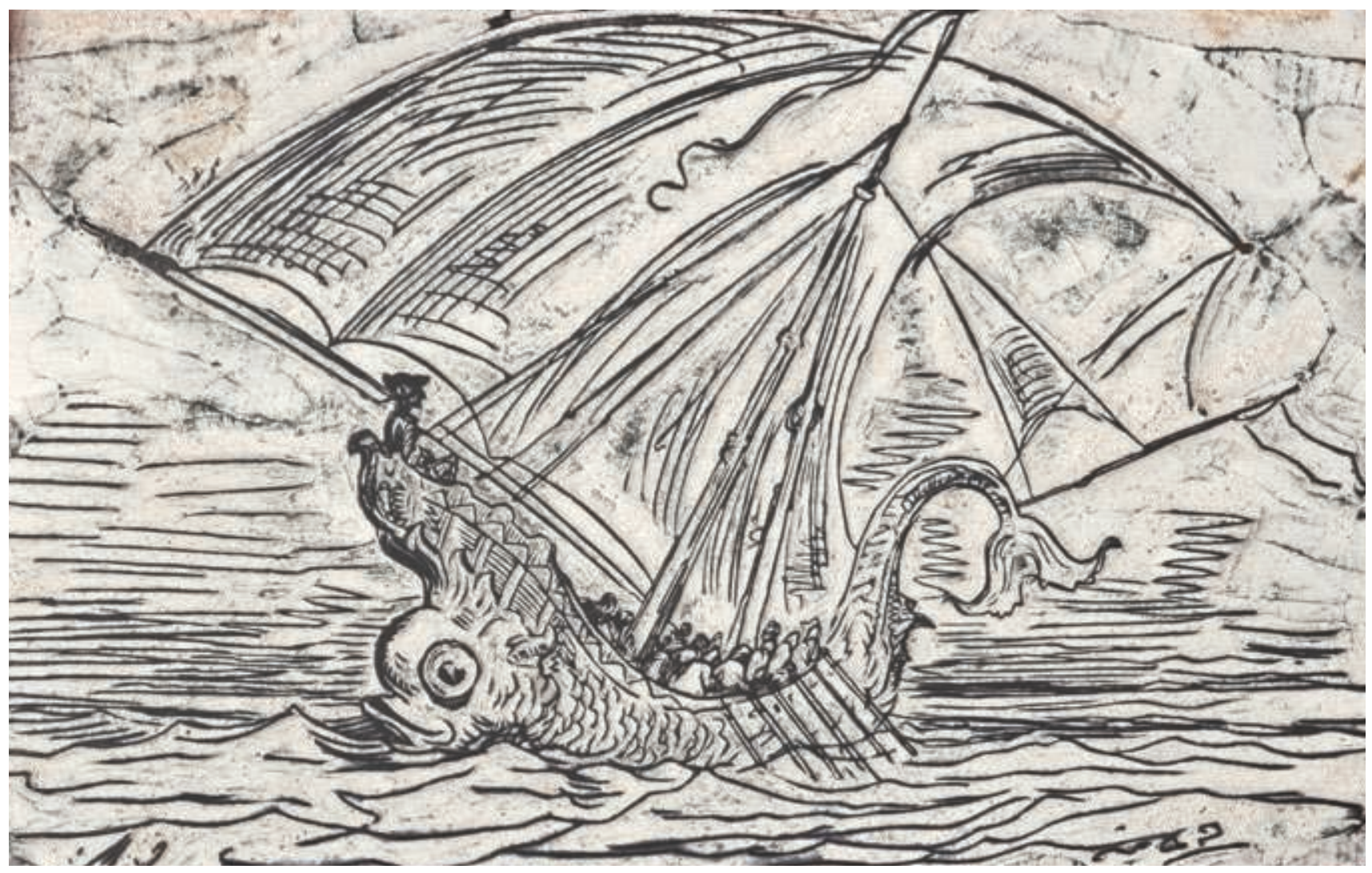

Bois de Gustave Doré pour l'illustration des Aventures du baron de Münchhausen : « vaisseau fantôme », Paris : Furne, 1862, page 112

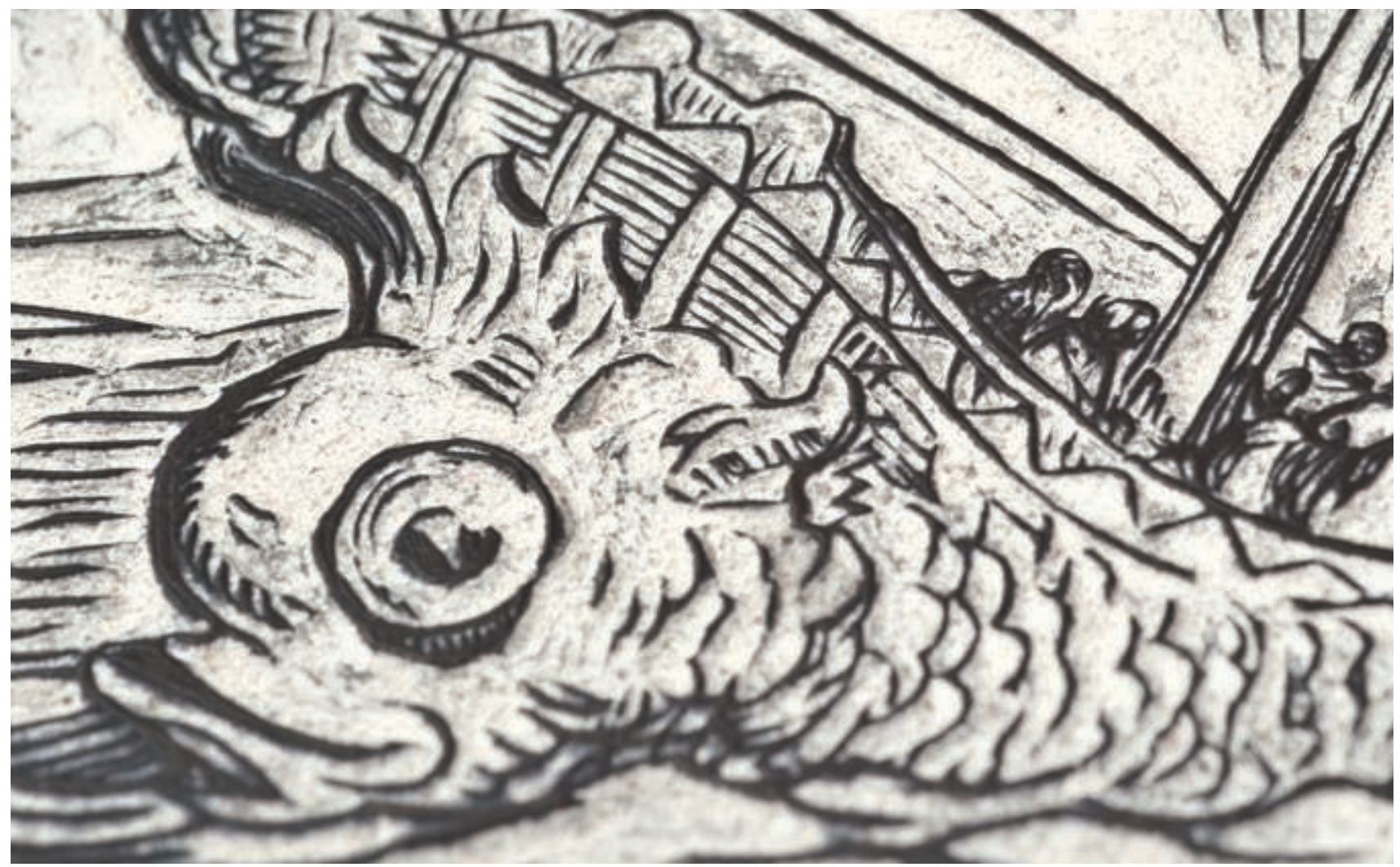




\section{TROIS BOIS GRAVÉS DE GUSTAVE DORÉ}

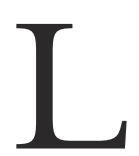

es fonds de la Réserve de la BNU abritent, outre un nombre important d'éditions illustrées par Gustave Doré, trois des bois utilisés par l'artiste pour l'illustration de l'édition des Aventures du baron de Münchhausen parue en 1862. La technique de la gravure sur bois était le procédé favori de Doré, qui l'employa à de nombreuses reprises dans son travail d'illustrateur. Doré était un graveur quasiment autodidacte, prônant tout au long de sa carrière des techniques artisanales qui lui permettaient de parvenir aux résultats les plus satisfaisants pour les nombreuses éditions de luxe auxquelles il participa. Il remit petit à petit la gravure sur bois à la mode au milieu du $19^{\text {e }}$ siècle, en développant de nouvelles techniques. Vers 1860 en effet, il fait figure de promoteur de la nouvelle gravure sur bois, dite "d'interprétation " ou " de teinte ». Depuis ses débuts, il s'était montré assez peu satisfait du travail des xylographes. Lorsqu'il s'agissait de respecter ses créations, il était extrêmement pointilleux et n'hésitait pas à être autoritaire face à ses graveurs. Ce n'est qu'à partir de 1856 qu'il collabora régulièrement avec trois ouvriers de talent : François Rouget, Octave Jahyer et Jean Gauchard. Son plan de publication visait à développer une élite de lecteurs souhaitant acquérir des éditions de luxe, dont le prix équivalait parfois au salaire mensuel d'un employé de commerce. Ces in-folios qui mettent en valeur les chefsd'œuvre de la littérature étaient destinés à être posés en évidence sur les tables des salons pour être lus, et surtout pour être vus.

Au milieu du $19^{\mathrm{e}}$ siècle, le genre du roman d'aventures connaît un véritable âge d'or. Gustave Doré vit alors une période de travail intense : entre 1862 et 1865 , il réalise pas moins de mille nouvelles gravures pour Don Quichotte, $L a$ Légende de Croque-Mitaine ou Le Paradis perdu de Milton. C'est tout naturellement qu'il accepte de participer à l'illustration des Aventures du baron de Münchhausen traduites par le fils de son ami Théophile Gautier.
Le travail de Doré souligne la dimension humoristique et fantasque des péripéties de ce roman important de la littérature populaire allemande. Il a grandement participé à la popularité des péripéties que le véritable baron de Münchhausen prétendait avoir vécues au milieu du $18^{\mathrm{e}}$ siècle, et les thèmes mis en image par Doré ont notablement contribué à la notoriété du récit de ses aventures, inscrivant certaines représentations dans l'imaginaire collectif. La célèbre image du baron s'envolant sur un boulet de canon (reprise en particulier lors de l'adaptation cinématographique de l'ouvrage en 1943) en est certainement l'un des meilleurs exemples.

Les trois bois possédés par la BNU illustrent les aventures racontées par le baron lors de son séjour dans l'Empire ottoman. La plus importante des gravures illustre une scène de harem : le baron étant arrivé à Constantinople, au terme de nombreuses aventures en mer, se voit proposer les compagnes de son choix par le souverain de la Sublime Porte. Il s'agit là d'un exemple parmi d'autres des récits extraordinaires contés par celui qu'on a surnommé le " Lügenbaron " (le " baron mensonge ") aux hôtes de marque qu'il recevait dans son château du Nord de l'Allemagne, et qui furent publiés d'abord dans des revues, puis en traduction anglaise et à nouveau en allemand, sous la plume du poète Gottfried August Bürger.

Les bois gravés de Gustave Doré sont relativement rares dans les collections publiques. La particularité de ceux conservés à la BNU réside dans le fait qu'ils correspondent tous les trois à la même œuvre.

Témoins des techniques de gravure que Doré maîtrisait à la perfection, ces bois illustrent l'intense activité créatrice de cet artiste qui pourtant ne cessa jamais de considérer cette activité comme mineure et d'affirmer qu'il n'illustrait des ouvrages que pour " payer ses couleurs et ses pinceaux».

\section{Jérôme Schweitzer}




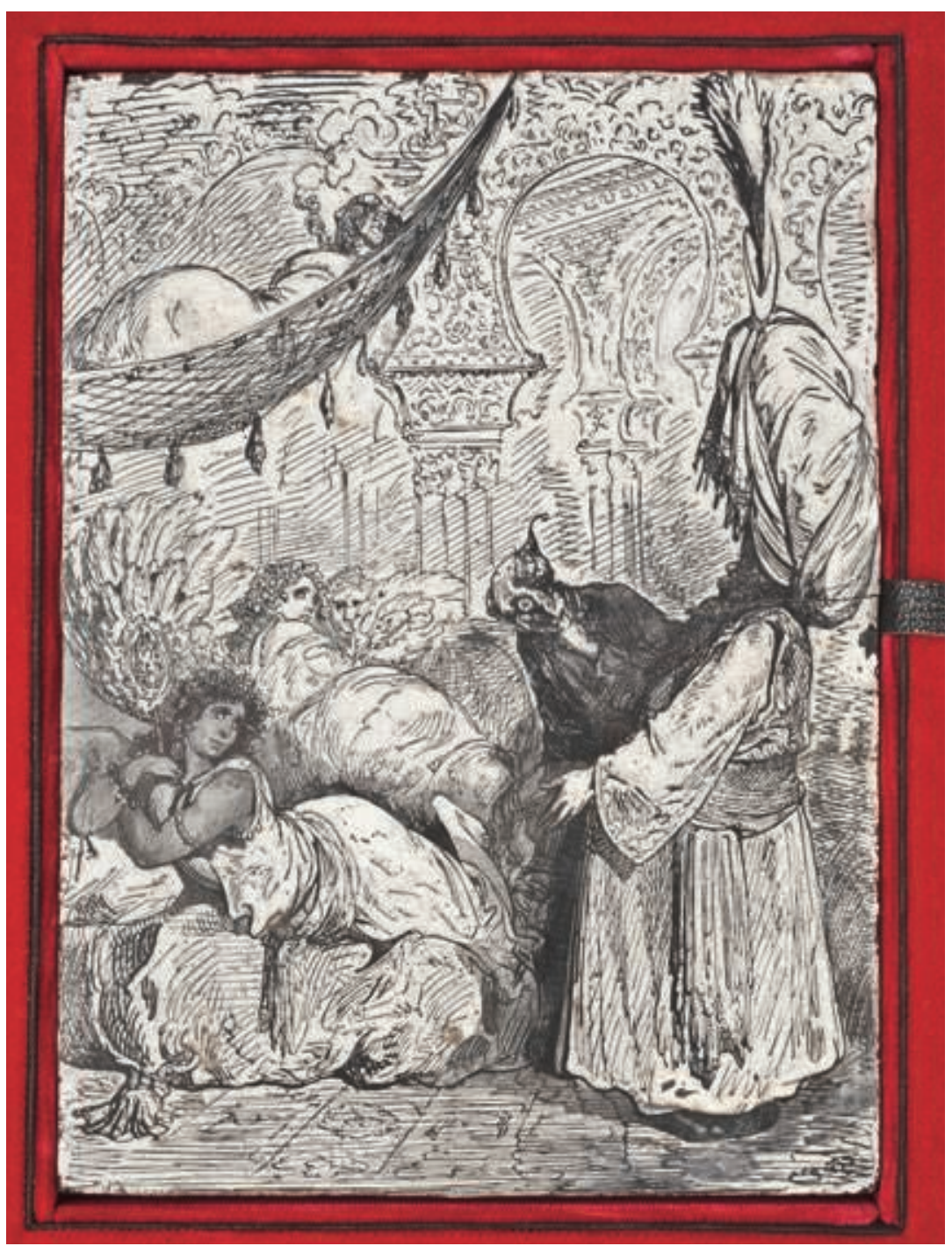

Bois de Gustave Doré pour l'illustration des Aventures du baron de Münchhausen : « scène de harem », Paris : Furne, 1862, page 129 ( Sa Hautesse me permet de choisir autant de dames que je voudrais »)

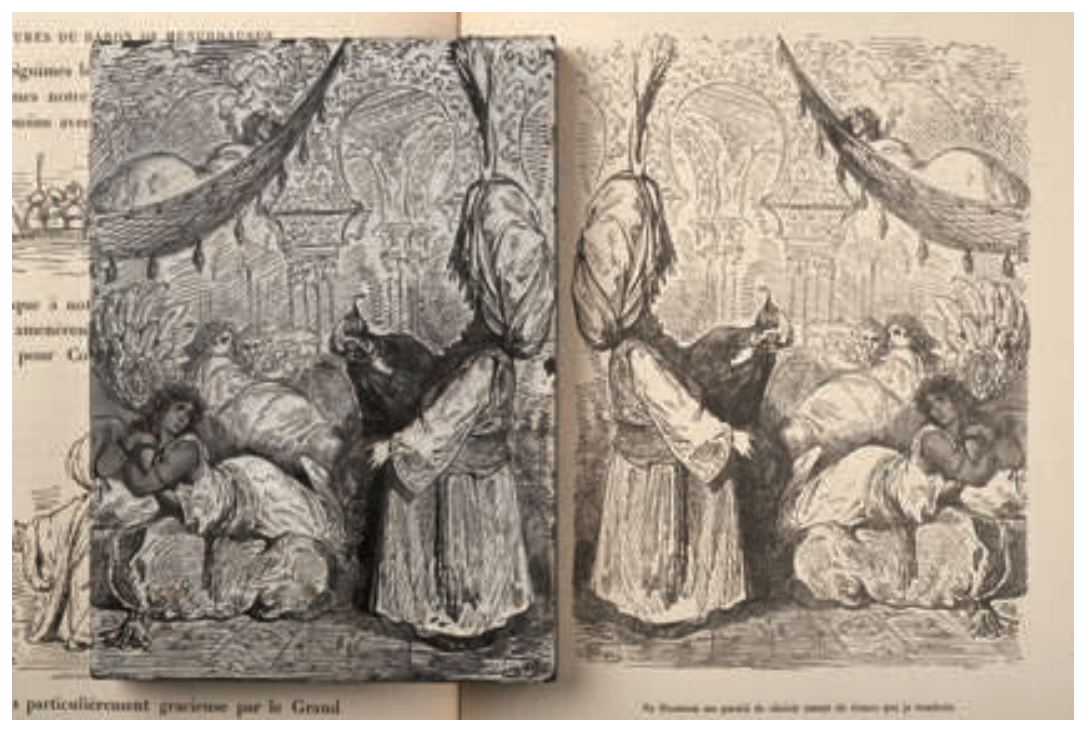

Le bois et la page illustrée après gravure 


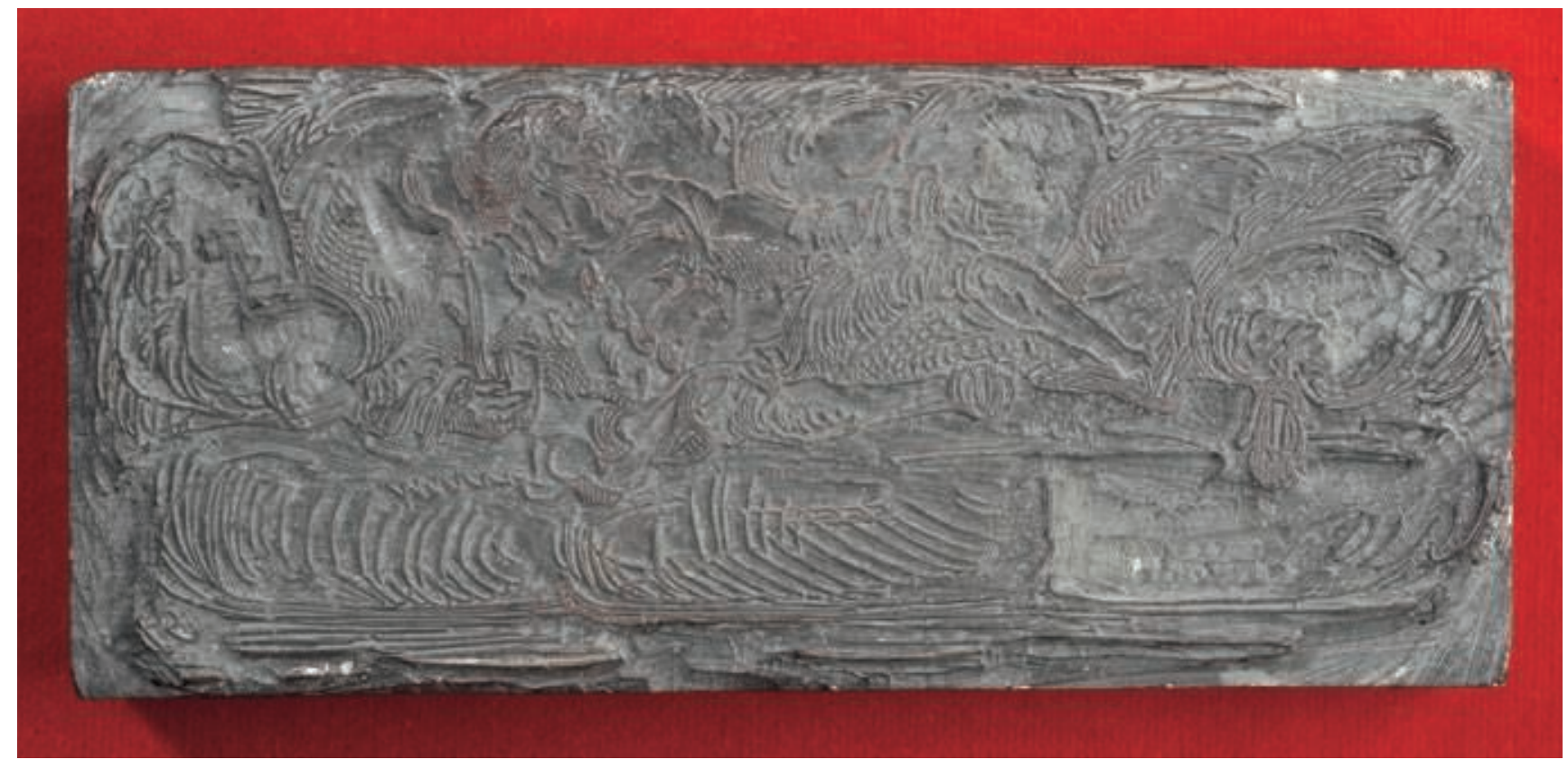

Bois de Gustave Doré pour l'illustration des Aventures

du baron de Münchhausen, Paris : Furne, 1862, page 151

( "Le baron va raconter son histoire de la défense de Gibraltar ")

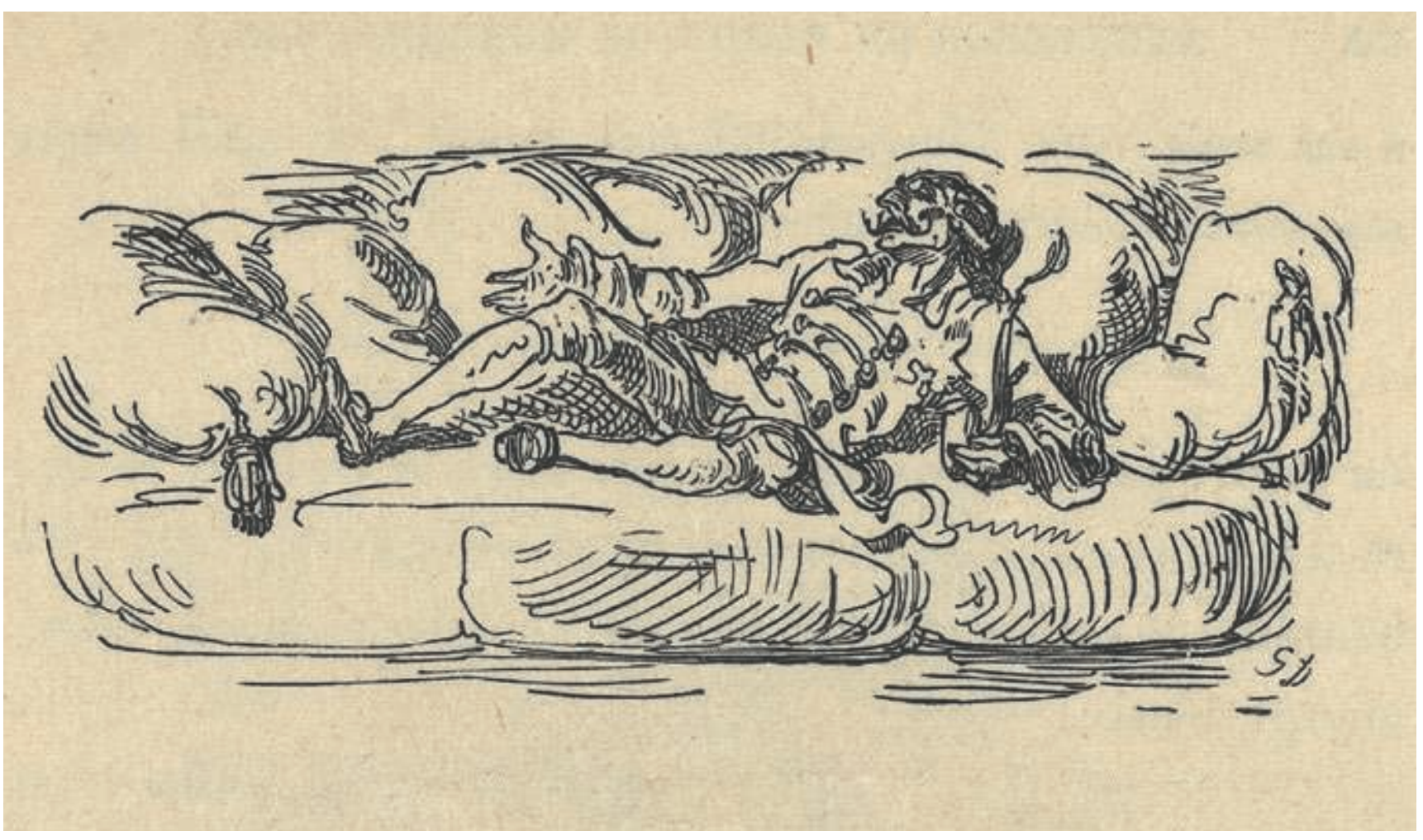

La même scène gravée, dans l'édition de 1862 